\title{
The influence of AlSi10Mg recycled powder on corrosion-resistance behaviour of additively manufactured components: mechanical aspects and acoustic emission investigation
}

\author{
Claudia Barile $^{1} \cdot$ Caterina Casavola $^{1} \cdot$ Vimalathithan Paramsamy Kannan ${ }^{1} \cdot$ Gilda Renna $^{1}$
}

Received: 27 October 2021 / Revised: 17 December 2021 / Accepted: 3 January 2022 / Published online: 24 January 2022

(c) The Author(s) 2022

\begin{abstract}
The effects of using recycled AlSi10Mg aluminium alloy powders on the mechanical properties and the corrosion-resistance behaviour of the components manufactured via selective laser melting (SLM) were analysed. The microstructural results show that the utilisation of recycled powder causes coarsening of interdendritic Si-network, especially along the melt pool boundaries of the SLM specimens. The corrosion resistance of the samples was evaluated by means of neutral salt spray (NSS) tests for $1000 \mathrm{~h}$ and mass loss measurements. The corrosion behaviour, in terms of surface roughness, density and porosity, however, remains almost the same between the samples produced by virgin and recycled powder. In addition to this, a passive NDE tool has been used to investigate and study the impact of powders on the corrosion performance of the alloy: Acoustic Emission (AE) technique. SEM observations allowed to highlight the morphological differences in the surface of the test specimens induced by the exposure condition. Thus, it was possible to correlate the AE results to corrosion mechanisms activated on the surfaces of the test specimen. A good correlation between the corrosion-resistance behaviour and the AE test results were obtained. Finally, the mechanical properties before and at the end of the accelerated corrosion were evaluated according to the yield strength, tensile strength, and elongation at breakage. The results showed comparable mechanical properties for the samples produced using both virgin and recycled powders. Besides, no notable influence of the exposure to corrosive environment on the mechanical performance was observed.
\end{abstract}

Keywords AlSi10Mg alloy $\cdot$ Additive manufacturing (AM) $\cdot$ Selective laser melting (SLM) · Aluminium corrosionresistance behaviour $\cdot$ Acoustic emission (AE)

\section{Introduction}

Additive Manufacturing (AM) has revolutionised the way of conceiving, designing and producing high value components and has given rise to new opportunities and important market prospects. Recently, the use of components fabricated with AM technologies has increased in several industrial applications, including aerospace, automotive and marine industries, that require the use of metallic materials capable of withstanding severe thermal and mechanical stress, even in very hostile environments. Selective laser melting (SLM), which is also known as

Claudia Barile

claudia.barile@poliba.it

1 Dipartimento di Meccanica, Matematica e Management, Politecnico di Bari, Via Orabona 4, 70126 Bari, Italy
Direct Metal Laser Sintering (DMLS), is one of the AM technology able to produce a metal part by selectively melting metal powder onto a bed along a scanning path using a laser beam. Compared to the traditional manufacturing routes, SLM processes has inherent advantages owing to its fewer restrictions in shape (does not require a mould), short lead times and high resolution for complex shapes and structures. Besides, the overhead cost of operation is less for SLM in manufacturing complex shapes and structures with high resolution when compared to the traditional manufacturing techniques. Moreover, as indicated by Yusuf et al. [1], the extremely high cooling-rates during SLM process, on the order of $10^{6}-10^{8}{ }^{\circ} \mathrm{C} / \mathrm{s}$, can produce very fine-grained structure in the SLM parts, characterised by increased mechanical properties, including higher yield and tensile strengths, better corrosion resistance and enhanced fatigue life. On the other hand, it has some limitations such as the high price of the feedstock (virgin metal 
powder) that leads to the cost-intensive printed components, and wastage of material. Ardila et al. [2] discussed the amount of wastage incurred in the traditional and AM manufacturing processes. The incurring costs in these techniques have been discussed by Tang et al. [3]. In the recent works by Rafieazad et al. [4] and Asgari et al. [5], the reduction of cost using the collected powder from the previous SLM construction process was discussed. Several research works have showed that the shape, size distribution and microstructure of all the collected powders after the completion of each building cycle were not identical to the virgin powder due to both the high temperature of the powder bed in the preheating stage (Aboulkhair et al. [6]) and the interaction between the virgin powder and the laser close to the parts that are being built (Olakanmi et al. [7]). The microstructural and morphological changes of the recycled powder deserve particular attention because typically they can adversely affect the build quality of new parts. Therefore, to use the recycled powder in the fabrication of new parts, particularly in aerospace industries, in which quality control and standardisation is of high importance, it is necessary that the mechanical and corrosion properties should be comparable to parts produced using certified virgin powders. Recently, a wide variety of metal components are fabricated using different feed material such as alloy 718 by Ardila et al. [2], sintered stainless steel by Renna et al. [8], $2024 \mathrm{Al}$ alloy by Tan et al. [9] and AlSi10Mg by Yusuf et al. [1] using SLM. Campbell [10] and Renna et al. [11] have argued that in aeronautical industries, the $\mathrm{Al}$ alloys are among the lightweight materials most commonly employed for producing complexshaped components. Particularly, the AlSi10Mg alloy is the mostly used among the other available $\mathrm{Al}$ alloys owing to its high strength and stiffness-to-weight ratio and the good corrosion resistance. Revilla et al. [12] has studied the corrosion behaviour of AlSi10Mg alloy and have evidently proved the same. Moreover, it has become one of the most applicable $\mathrm{Al}$ alloys for the SLM technique, due to its excellent welding performance, good melt fluidity, low Coefficient of Thermal Expansion (CTE) and high recycling potential, as indicated by Porter [13] and Dong et al. [14]. Experimental work by Maamoun et al. has showed the recycling potential of AlSi10Mg in particular [15]. The hypoeutectic composition of Al-Si in this alloy, as shown by Kempen et al. [16] indicates its applicability in casting processes. The microstructure of the cast counterpart of $\mathrm{AlSi} 10 \mathrm{Mg}$ is characterised with the presence of a coarse and acicular eutectic Si phase owing to the low cooling rate $\left(10^{2}{ }^{\circ} \mathrm{C} / \mathrm{s}\right.$ or less $)$. Nevertheless, it has been recognised that this coarse and acicular-shaped eutectic $\mathrm{Si}$ phase often cause cracks in cast AlSi10Mg when placed under tensile load. In the recent works of Asgari et al. [5] and Yusuf et al. [1], it has been shown that the SLM process has significantly improved the mechanical properties of AlSi $10 \mathrm{Mg}$ alloy by producing a finer microstructure, which is characterised by a homogenous $\mathrm{Si}$ phase distributed in the $\mathrm{Al}$ matrix.

The effects of SLM process parameters on the microstructure, mechanical properties, residual stress, porosity and surface roughness of AlSi10Mg alloys were studied extensively. Louvis et al. [17] studied the influence of the laser power on the microstructure and mechanical properties of AlSi10Mg alloy, while Trevisan et al. [18] provided a detailed literature survey on this topic. Weingarten et al. [19] studied the hydrogen porosity in SLM components by varying the process parameters and Rosenthal et al. [20] studied the fracture mechanisms. Zhao et al. [21] has extended this research to study the electrical sensitivity of AlSi10Mg components, impregnated with carbon nanotubes. However, little attention has been paid for the evaluation of the corrosionresistance behaviour of SLM components manufactured using AlSi10Mg aluminium alloy powders. Particularly, the attention on using recycled AlSi10Mg alloy as feed material for SLM components were seldom studied. The study of corrosion-resistance is of great importance since corrosion is one of the primary causes of degradation, which consequently results in the reduction of the mechanical performance of the components/structures. In this research work, a comprehensive analysis on the corrosion-resistance behaviour of SLM components prepared from virgin and recycled AlSi10Mg feed material is studied. The study focuses on the intrinsic properties such as mass loss, density loss and surface roughness of the SLM samples exposed to different durations in the NSS test chamber, which simulates the condition of environmental attack. In addition to that, the tensile mechanical properties and the hardness properties are also studied. The passive NDE tool, acoustic emission (AE) technique is used for monitoring the corrosion progression in the samples exposed to the corrosion environment. Finally, a comprehensive surface morphology and fractographic analysis on the effect of the exposure to the corrosion environment on the virgin and recycled AlSi10Mg SLM components are studied using SEM.

\section{Materials and methods}

\subsection{Material characterisation of SLM samples}

The feed material used in this work was AlSi10Mg aluminium alloy powder of density $2.67 \mathrm{~g} / \mathrm{cm}^{3}$ and a melting range of $570{ }^{\circ} \mathrm{C}-590{ }^{\circ} \mathrm{C}$. The chemical composition of $\mathrm{Al}$ alloy powder is presented in Table 1.

The dog bone-shaped samples were deposited by Selective Laser Melting (SLM) process in RenAM 500 M system using virgin and recycled AlSi $10 \mathrm{Mg}$ aluminium alloy 
Table 1 Chemical composition of the AlSi10Mg aluminium alloy powder

\begin{tabular}{lllllllllllllll}
\hline Components & $\mathrm{Al}$ & $\mathrm{Si}$ & $\mathrm{Mg}$ & $\mathrm{Fe}$ & $\mathrm{N}$ & $\mathrm{O}$ & $\mathrm{Ti}$ & $\mathrm{Zn}$ & $\mathrm{Mn}$ & $\mathrm{Ni}$ & $\mathrm{Cu}$ & $\mathrm{Pb}$ & $\mathrm{Sn}$ \\
\hline Weight $\%$ & $\mathrm{Bal}$ & 11 & 0.45 & $<0.25$ & $<0.2$ & $<0.2$ & $<0.15$ & $<0.1$ & $<0.1$ & $<0.05$ & $<0.05$ & $<0.02$ & $<0.02$
\end{tabular}

powders. The recycled powder from unmelted powder collected from previous fabrication cycles is used. The dimensions and schematic diagrams of the samples are shown in Fig. 1. Nd:YAG laser source of maximum power output $400 \mathrm{~W}$ and wavelength $1.064 \mu \mathrm{m}$ was used for melting the AlSi10Mg virgin and recycled powder. The laser beam of spot diameter $200 \mu \mathrm{m}$ was traced over the powder deposited on the preheated bed at a speed of $100 \mathrm{~mm} / \mathrm{s}$ for achieving a single-track energy density $20 \mathrm{~J} / \mathrm{mm}^{2}$. The thickness of each layer of the SLM process was $20 \mu \mathrm{m}$. The recoater was moved along the $\mathrm{Y}$ axis while the laser traced and melted the powder along the $X$ axis. The SLM samples were built over a heated platform. Post-scanning, the specimens were air cooled and the stress was relieved by keeping the ambient temperature to $300{ }^{\circ} \mathrm{C} \pm 10{ }^{\circ} \mathrm{C}$ for about $2 \mathrm{~h}$. Similar procedure was followed by Barile et al. [22] in the manufacturing of AlSi10Mg components in different orientations, which showed improved mechanical properties.

Microstructural analysis was performed on the Short Transverse-Longitudinal section (ST-L plane) of the samples (Fig. 1). First, the cross-sectioned SLM samples were individually mounted, then mechanically ground, polished and finally etched at room temperature using Keller's reagent (solution of $2 \% \mathrm{HF}, 3 \% \mathrm{HCl}, 5 \% \mathrm{HNO}_{3}$ and $90 \% \mathrm{H}_{2} \mathrm{O}$ ). The morphology and microstructure of the as-received and post-corrosion test samples were characterised using Nikon Eclipse TE2000-U Optical Microscope (OM) supported by a computer-assisted image analysis (NIS Elements AR), and Zeiss EVO-MA10 scanning electron microscope (SEM).

Intrinsic properties, such as mass and density, and surface roughness of the as-received SLM samples and samples exposed in the salt spray chamber up to $1000 \mathrm{~h}$ were also determined using traditional methods. For evaluating the
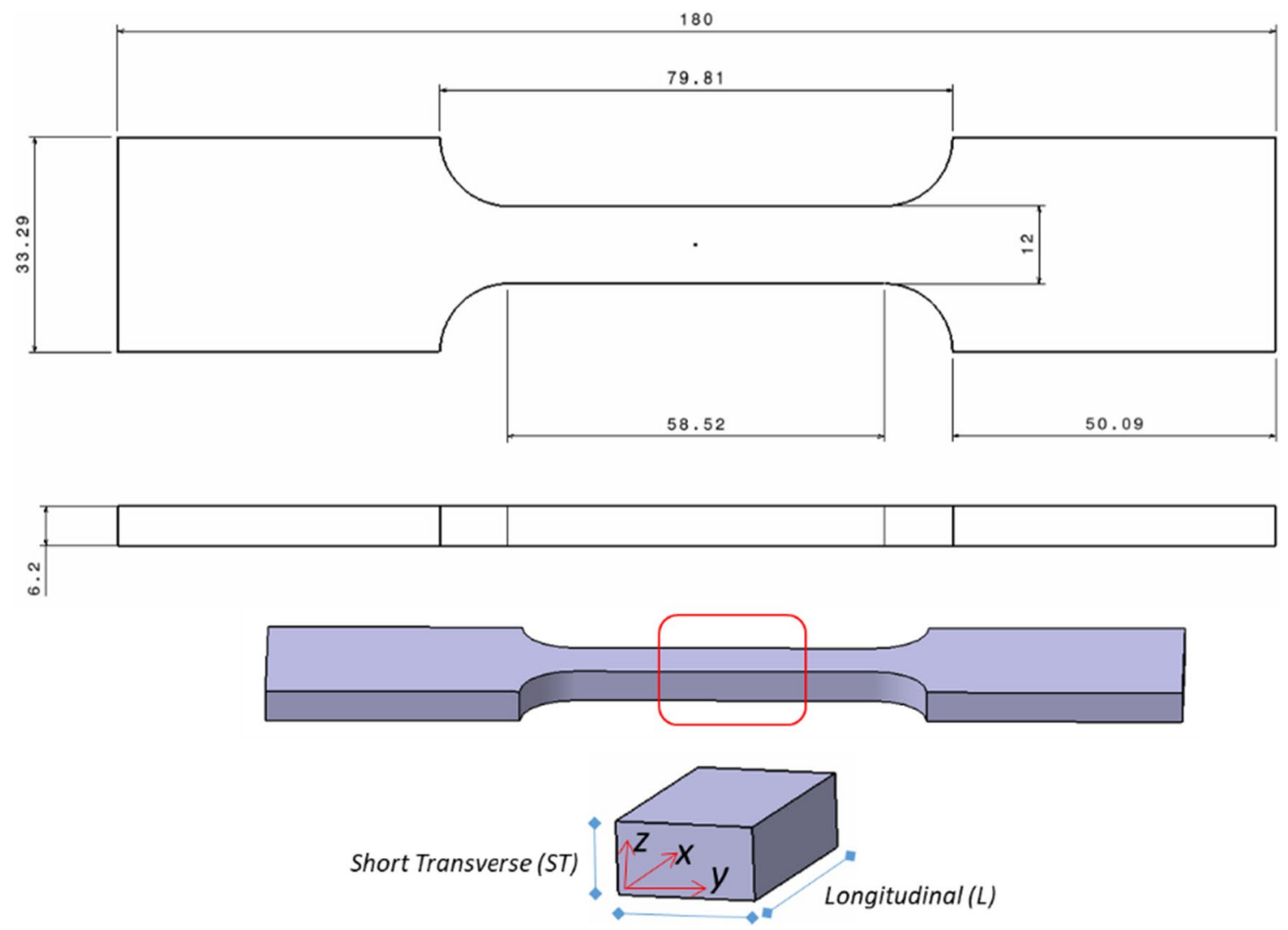

Long Transverse (LT)

Fig. 1 Dimensions (in mm) and schematic diagrams of the AlSi10Mg dog bone-shaped Specimens 
mass loss in the samples over the different exposure time in the NSS chamber, the PCE-LS500 analytical balance with $0.1 \mathrm{mg}$ sensitivity was used, while the density was calculated using the water displacement method (via the Archimedes method).

The surface roughness of SLM samples pre- and postcorrosion treatment was measured in accordance with ISO 4287-1997, using a Taylor Hobson Surtronic 25 portable profilometer with a cutoff length of $0.8 \mathrm{~mm}$ and a measurement length of $8 \mathrm{~mm}$. Roughness parameters, $R a$ and $R t$ were evaluated. $R a$ is the roughness average value that represents the arithmetic average of the absolute values of the roughness profile ordinates, while $R t$ is roughness total height value that indicates the maximum peak to valley height within the evaluation length. The roughness reported was the average of five values scanned from different areas on the coating surface.

In accordance with ASTM E-384, Vickers hardness tests with the load of $1000 \mathrm{~g}$ for $15 \mathrm{~s}$ were performed. The indentations were carried out on the three sections of sample ( $X Y$, $Y Z$ and $X Z$ plane) using KB Prüftechnik type hardness tester. Ten measurements randomly at ten different points were carried out to calculate the average hardness values of sample substrate. These measurements were carried out both on the samples prepared from virgin and recycled AlSi10Mg powder.

\subsection{Salt spray corrosion test}

Neutral salt spray (NSS) test chamber, Weiss Technik SCKWT 450, was used to produce simulated corrosion environment for exposing the SLM samples. NSS tests were carried out according to the ASTM B117 standard [23], in which dog bone-shaped samples realised using virgin and recycled AlSi10Mg alloy powders were exposed to $5 \% \mathrm{NaCl}$ solution in a salt spray cabinet, operated at $35^{\circ} \mathrm{C}$. Samples were mounted at an inclination of $15^{\circ}-30^{\circ}$ from vertical. The humidifier pressure and temperature were set at 0.98 bar and $48{ }^{\circ} \mathrm{C}$, respectively. Then, the micrometric salt spray (fog) was produced inside the chamber, which created a highly corrosive environment. The chosen exposure time intervals (levels), selected from among the exposure levels suggested by DIN EN ISO 9227 [24], were: 2, 6, 24, 48, 96, 168, 240, 480, 720 and $1000 \mathrm{~h}$. At the end of each level, two samples produced from virgin and recycled powders were taken from the chamber, washed with distilled water and then air-dried for further analysis.

\subsection{Acoustic emission (AE) test}

The corrosion progression inside the corrosion chamber is monitored using Acoustic Emission (AE) technique. $\mathrm{AE}$ records the elastic waves generated from the local irreversible deformation in the material. During corrosion, the formation of pits, spallation of corrosion products and the growth of the corrosion cracks are general sources of $\mathrm{AE}$ waves. In this study, the $\mathrm{AE}$ signals were recorded in the AlSi10Mg sample exposed to the corrosion environment. A piezoelectric AE sensor ISR 15, which is specifically designed for meeting the necessity of harsh environment was used. The sensor was mounted and silicone grease was smeared between the surface of the sample and the transducing element of the sensor to improve the acoustic coupling. The sensor was held firmly to the sample surface by a clip.

The threshold for acquisition was set as $25 \mathrm{~dB}$ and the sensor signals were preamplified by $40 \mathrm{~dB}$ using $2 / 4 / 6 \mathrm{AE}$ preamplifier. All the acoustic signals were recorded at a sampling rate of 1 mega sample per second (1 MSps). For analysing the acoustic emission data, signal-based descriptor-frequency centroid and parameter-based descriptorscumulative counts and peak amplitude were used.

\subsection{Tensile tests}

Static tensile tests on the as-received specimens and after each exposure time intervals were performed using an MTS uniaxial electro-mechanics machine of maximum load capacity $30 \mathrm{kN}$ under displacement-controlled mode with crosshead speed of $2 \mathrm{~mm} / \mathrm{min}$, according to the EN 10002-1 standard. Subsequently, the tensile characteristics, yield strength (YS), ultimate tensile strength (UTS), Young's modulus (EI) and elongation at break $(\varepsilon \%)$ were determined. In addition, a fractographic study of the fracture surface of the samples after the tensile tests was carried out using SEM.

\section{Results and discussion}

\subsection{SLM AIMg10Si sample features and microstructures}

\subsubsection{AIMg10Si sample features}

The images of the three sections of the polished SLM samples fabricated using virgin $\left(S_{\mathrm{PV}}\right)$ and recycled $\left(S_{\mathrm{PR}}\right)$ AlSi10Mg alloy powder are shown in Fig. 2. As shown in Fig. 2, both SLM-AlSi10Mg samples $\left(S_{\mathrm{PV}}\right.$ and $\left.S_{\mathrm{PR}}\right)$ are affected by some defects. The main defects detected in the samples occur as voids of different morphology: small spherical voids (gas pores, $n^{\circ} 1$ in Figs. 2 and 3 ) and large, near-spherical shape voids (Keyhole pores, ${ }^{\circ} 2$ in Figs. 2 and 3) that distributed along the edges of samples. The formation of gas pores ( $\operatorname{size} \leq 10 \mu \mathrm{m}$ ) is mainly due to the entrapment of inert gas in the melt pool during the melting of the feed powder. This was observed by Tan et al. [9] in the manufacturing of $2024 \mathrm{Al}$ alloy due to insufficient 

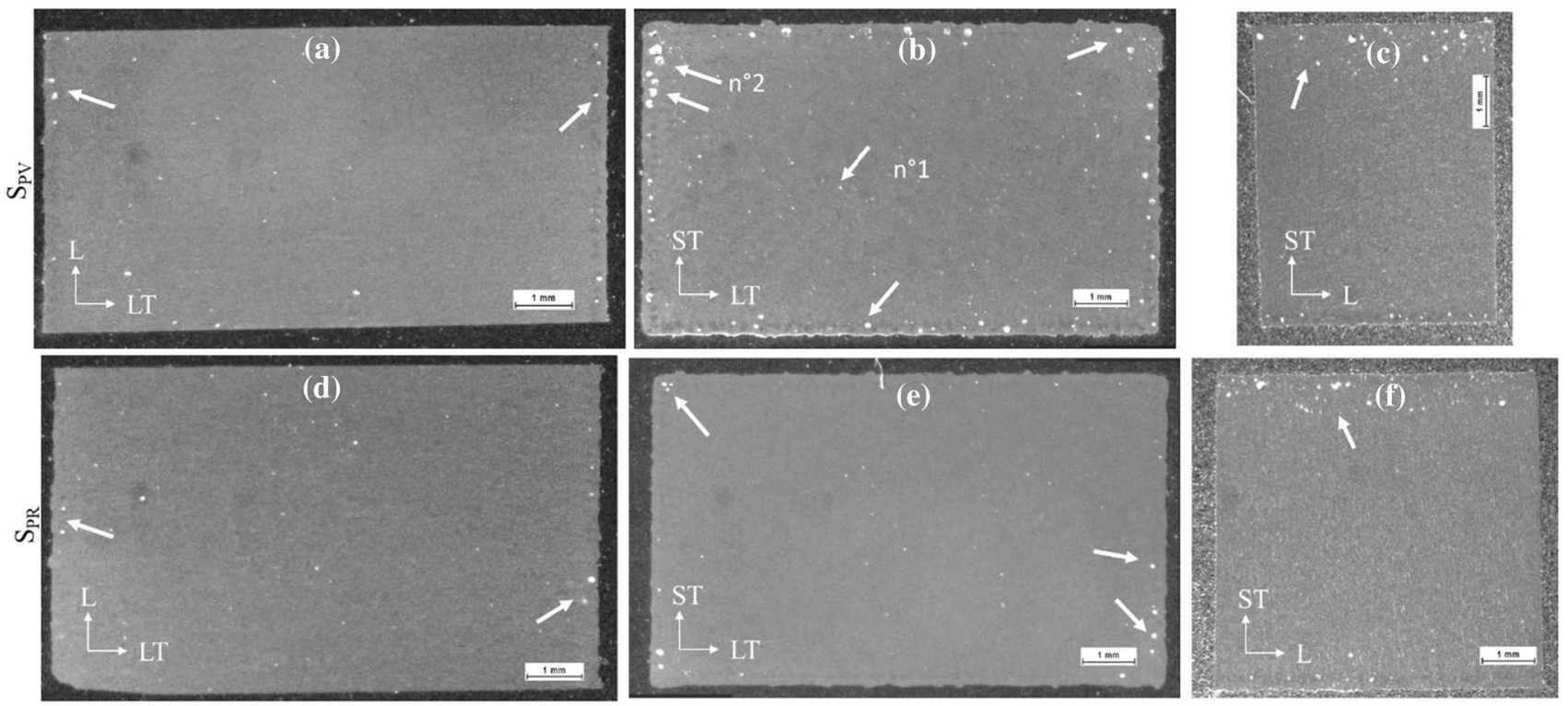

Fig. 2 Micrographs of polished SLM samples fabricated using virgin $\left(S_{\mathrm{PV}}\right)$ and recycled $\left(S_{\mathrm{PR}}\right)$ AlSi10Mg alloy powder. $S_{\mathrm{PV}}$ sample: a L-LT plane (Longitudinal-Long Transverse section), b ST-LT plane
(Short Transverse-Long Transverse section) and c ST-L plane (Short Transverse-Longitudinal section). $S_{\mathrm{PR}}$ sample: d L-LT plane, e ST-LT plane and f ST-L plane
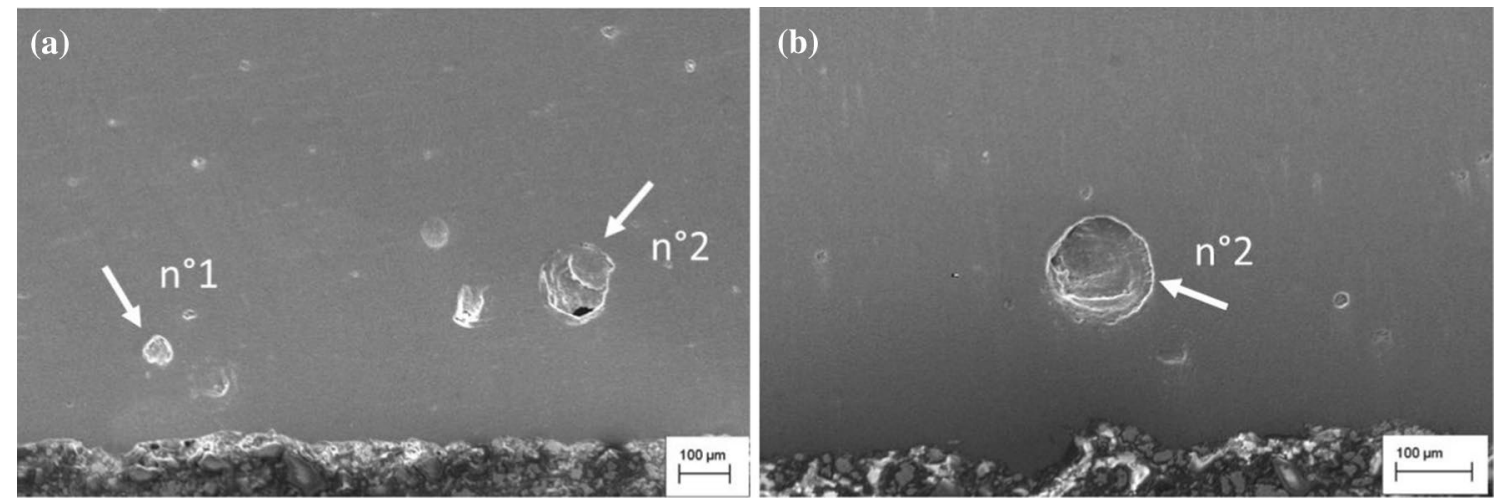

Fig. 3 SEM micrographs showing the typical voids formed in the SLM AlSi10Mg alloy: small spherical voids $\left(\mathrm{n}^{\circ} 1\right)$ and large, near-spherical shape cavities $\left(\mathrm{n}^{\circ} 2\right)$

laser energy. However, this is not the case in this study. Perhaps, this could be due to the presence of gas in the feed material before melting, as mentioned by Yusuf et al. [1]. While the evaporation of the alloying elements and hydrogen that realised from the moisture $\left(\mathrm{H}_{2} \mathrm{O}\right)$ on the powder surfaces could also be the reason. Moreover, the entrapped gas inside the initial raw powder generated during gas atomisation process is believed to be reason for these spherical pores in the samples. On the other hand, according to Kempen et al. [16], the formation of Keyhole pores (sizes up to $100 \mu \mathrm{m}$ ) was considered as a consequence of the improper melting of the powders, owing to the lack of thermal conduction between the powders during the laser melting process. From the OM images in
Fig. 2, a lower number of visible pores within $S_{\mathrm{PR}}$ sample than that $S_{\mathrm{PV}}$ ones were noticed. This difference can be clearly seen while comparing the Fig. $2 b$ and e. In particular, it can also be observed that using recycled powders in the fabrication of SLM sample had resulted in the formation of fewer and smaller keyhole porosities compared to the virgin sample. The direct cause of the loss of porosity in the $S_{\mathrm{PR}}$ samples might be related to an increased powder packing density. The combination of a wide range of fine and coarse particles collected after completion of building cycle possibly could have increased the powder packing density. Besides, the increased powder cohesion and inter-particle forces due to the highly active contact surface area of small particles along with coarse particles 
lead to higher thermal conductivity between them. This was explained and evidently shown by Tan et al. [25] in their work.

To evaluate and quantify the effect of recycled powder on the characteristics of the samples, the average hardness and porosity measurements on the as-polished surfaces of the two samples were performed (Table 2). The results indicate that the use of recycled powders does not affect the intrinsic properties of the SLM samples. In agreement to OM observations, the porosity percentage of the samples fabricated using recycled powder was lower than ones obtained using the virgin powder. It is important to note that this porosity percentage $(0.2 \%)$ can be considered as a low porosity level compared to the available values in experimental campaigns conducted by Read et al. [26] and Aboulkhair et al. [27]. It has been indicated by Cordova et al. [28] that the higher particle size distribution in the recycled powder improves the flowability due to the presence of smaller number of fine particles. This will reduce the porosity of the final product. Besides, the porosity of an SLM component is affected by the process parameters rather than the pack density of the recycled feed material used. Moreover, the relative density of the $S_{\mathrm{PR}}$ sample calculated as the measured density divided by the theoretical density of AlSi $10 \mathrm{Mg}$ was equal to $98.4 \%$, which is comparatively higher than the $S_{\mathrm{PV}}$ sample (97.6\%). Unlike the porosity, a relatively lower average hardness values were observed for $S_{\mathrm{PR}}$ sample compared to the as-built $S_{\mathrm{PV}}$ sample, indicating a slight microstructural variation (Table 2). In addition, the average hardness value changed slightly along the three sections of the two samples. In the works of Read et al. [26] and Aboulkhair et al. [6], the morphology of the recycled AlSi10Mg powder shows changes such as particle elongation and satellite formation. Although these morphological changes do not affect the porosity in most cases, the surface roughness is affected. This possibly could be the reason why the $S_{\mathrm{PR}}$ sample has high density compared to $S_{\mathrm{PV}}$ sample. This variation, indicating anisotropy in their mechanical properties, is a function of the solidification microstructure. In particular, the Short Transverse-Long Transverse section (ST-LT plane) exhibited higher hardness value than that of the other two sections (L-LT and ST-L planes).

\subsubsection{Microstructures}

Optical and scanning electron micrographs on the ST-L plane parallel to the build direction of the AlSi $10 \mathrm{Mg}$ SLM samples are shown in Fig. 4a and b, respectively. In agreement with previous studies by Revilla et al. [12] and Maamoun et al. [15], the OM analysis revealed that the overall macrostructure and morphology of the melt pools in the SLM samples are independent of powder employed. The sample cross-section is characterised by several stacked melt pools having a well-defined interface (melt pool boundary), that were formed between them by the fusion and diffusion reactions. The layered structure can be seen in Fig. 4a, where some of those melt pools boundaries highlighted by dashed lines. As shown in Fig. 4a, melt pools have half-cylindrical shape, which is similar to the observation by Thijs et al. [29]. This cylindrical shape is the reflection of the Gaussian shape of laser beam power distribution, as explained by Maamoun et al. [15]. A closer look at the SEM micrographs also reveals the presence of narrow heat-affected zones (HAZ) on the boundary of the melt pools (seen the arrow in Fig. 4b) in the previously solidified layer, due to the heat treatment from the laser heat source. Therefore, three different zones can be distinguished within the SLM samples (Fig. 4b): melt pool, melt pool boundary and HAZ. The microstructure at the interface and within the melt pool was resolved at higher magnifications in Fig. 4c, d for the $S_{\mathrm{PV}}$ sample, while in Fig. $4 \mathrm{e}$, $\mathrm{f}$ for the $S_{\mathrm{PR}}$ sample. In both samples, the microstructure was characterised by a very fine dendritic solidification in which a eutectic Si-network is distributed in the Al-based matrix. Dendritic morphology is highlighted by the Si phase segregation (light colour) at the interspacing (Fig. 4c-f). It was observed that the microstructural morphology inside of the melt pools and at interface regions of the as-built samples is not the same but variable. Particularly, the microstructure of the melt pool boundaries exhibits a coarse dendritic microstructure, generally equiaxed with the existence of fine Si particles within them. The microstructure of the melt pools is characterised by cellular dendrites. The cellular dendrites, usually, grow anti-parallel to the main heat flux direction (perpendicular building direction). These different microstructure morphologies in the sample can be attributed to the variable solidification conditions in the volume of the molten pool

Table 2 Average hardness value $\left(\mathrm{HV}_{1 / 15}\right)$ measured on the three section, porosity percentage $(\%)$, weight and density of as-received SLM samples fabricated using both a virgin $\left(S_{\mathrm{PV}}\right)$ and recycled $\left(S_{\mathrm{PR}}\right)$ AlSi10Mg alloy powders

\begin{tabular}{llrrrrr}
\hline Sample & \multicolumn{2}{l}{ Vickers hardness $\left(\mathrm{HV}_{1 / 15}\right)$} & & Weight $(\mathrm{g})$ & Density $\left(\mathrm{g} / \mathrm{cm}^{3}\right)$ & \\
\cline { 2 - 5 } & ST-LT plane & ST-L plane & LT-L plane & & \\
\hline$S_{\mathrm{PV}}$ & $78.9 \pm 1.9$ & $77 \pm 1.4$ & $75.5 \pm 2.2$ & $60.378 \pm 0.001$ & $2.606 \pm 0.001$ & 0.7 \\
$S_{\mathrm{PR}}$ & $71.2 \pm 0.6$ & $69.6 \pm 1.2$ & $66.1 \pm 0.6$ & $60.172 \pm 0.001$ & $2.628 \pm 0.001$ & 0.2 \\
\hline
\end{tabular}




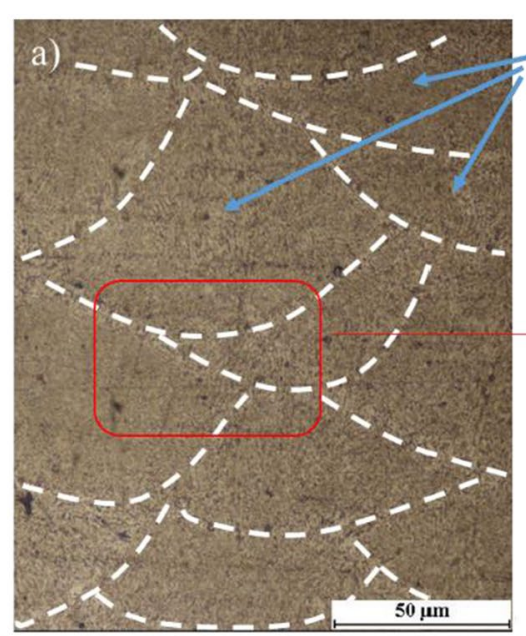

\section{Melting pools}
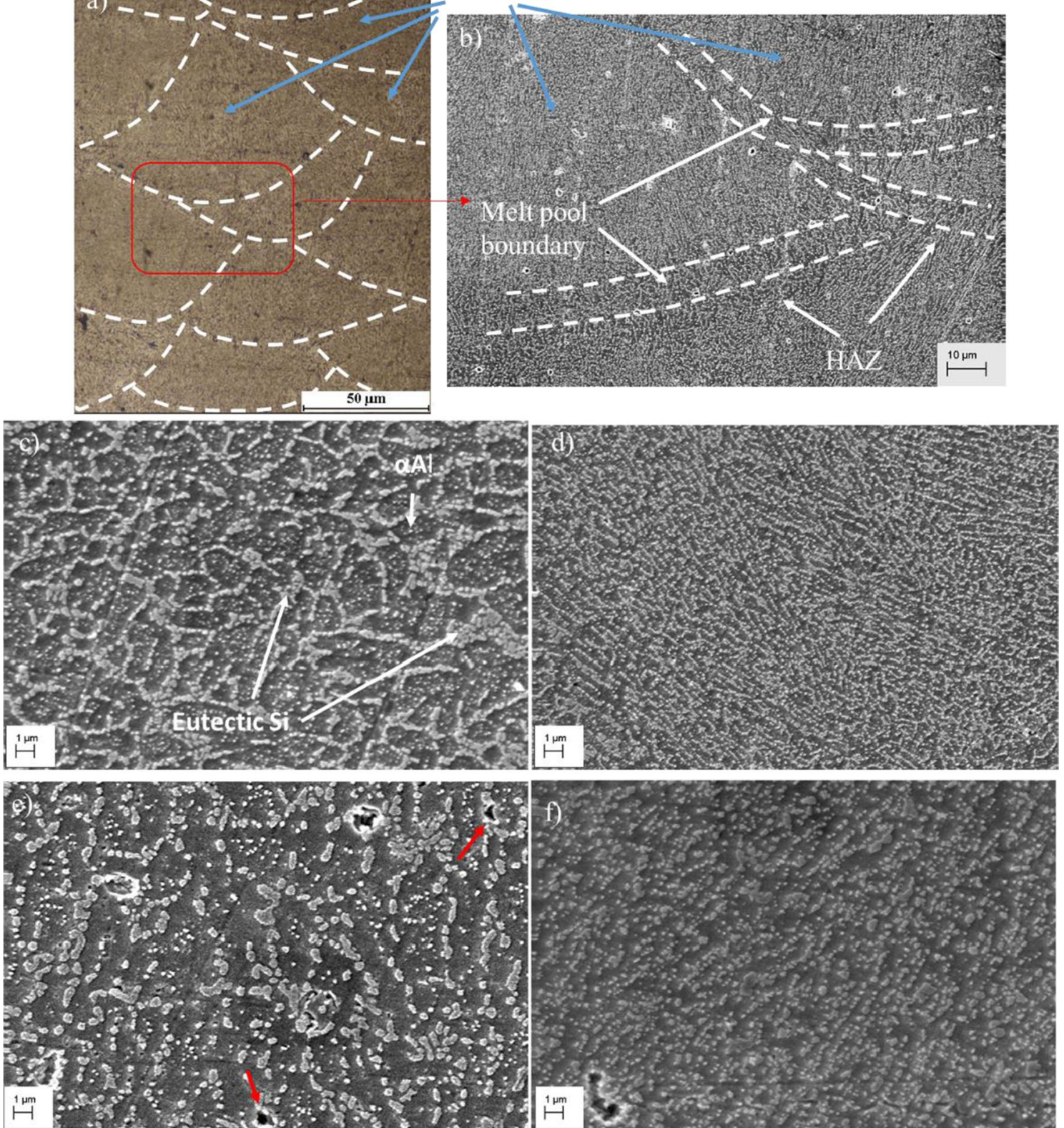

Fig. 4 Overview of SLM samples cross-section (ST-L plane): a OM image showing the microstructure parallel to build direction (the dashed white lines highlight the interface formed between the melting pools), b high-magnification SEM micrograph showing the three different regions: melt pool, melt pool boundaries and the heat affect zone (HAZ). $S_{\mathrm{PV}}$ sample: c microstructure at the melt pool boundaries and $\mathbf{d}$ within of the melting pool. $S_{\mathrm{PR}}$ sample: e microstructure at the melt pool boundaries and $\mathbf{f}$ within of the melting pool

respectively, in Fig. 4c, d and Fig. 4e, f, a difference in the scale of microstructure can be observed. Particularly, the $S_{\mathrm{PR}}$ sample shows a slightly coarser Si-network mostly at the melt pool boundaries. This microstructure coarsening can be related to the slower solidification rate across the melt pool. On the other hand, it is known that to melt the recycled powder, a larger portion of laser beam energy must be targeted rather than that to melt the virgin powder. This results in the formation of higher temperature melt pools, which are SEM micrographs of $S_{\mathrm{PV}}$ sample with the $S_{\mathrm{PR}}$ one, shown, 
characterised by a greater volume of material than that of the $S_{\mathrm{PV}}$ sample. Consequently, the regions at overlaps between the melt pools stay at higher temperatures for longer times, resulting in slower solidification rate, and thus, the formation of coarser microstructure and excessive solute segregation (eutectic $\mathrm{Si}$ ) from the liquid during solidification. Similar coarser microstructure and solute segregation were observed in the research works of Asgari et al. [5] and Rafieazad et al. [4]. Therefore, the results mentioned above justify the slight lower hardness value of $S_{\mathrm{PR}}$ sample than that $S_{\mathrm{PV}}$ (Table 2). Nonetheless, the scale of microstructure is very fine due to the high cooling rate of the melt, which is induced by the SLM process. Moreover, it must be noted that the as-built samples exhibit $\left(S_{\mathrm{PV}}\right)$ some submicron-scale pores, which are spherical and irregular in shape.

\subsection{Corrosion behaviour}

To evaluate the incidence of corrosion on the effectiveness of the usage of virgin or recycled powders, the samples were subjected to accelerated ageing treatments through Neutral Salt Spray tests (NSS test). The corrosion rate was calculated by mass loss, while the corrosion damages were evaluated by different methods, such as microscopical examination, Acoustic Emission (AE) and tensile test. The mass loss, expressed in $\mathrm{mg}$, was determined by reweighing and subtracting sample mass after exposure from its original mass, according to ASTM standard [23]. In other words, mass loss is nothing more than the net mass variation which generally, can be related with a mass gain if there is the formation of corrosion products or mass loss, if there are the spallation of corrosion products, and pit and crevice formation on the surface during the accelerated corrosion processes.

\subsubsection{NSS test}

The morphological features of the corroded surfaces were observed after $6,48,168,480$ and $1000 \mathrm{~h}$ exposure time through the secondary electron imaging (Fig. 5). As shown in Fig. 5a and 1, both the samples, before exposure to the NSS chamber $(0 \mathrm{~h})$, are characterised by a quite rough texture, resulted mainly from partially melted powder adhering to the surface (balling phenomena). Generally, it is known that the rough texture negatively affects the surface integrity and, therefore, corrosion strength. Revilla et al. [30] reported that a low roughness level in SLM samples results in high corrosion resistance. The balling phenomena is typical of the samples produced by SLM process. Tolochko et al. [31] argue that this mechanism is occurred when the energy density of the laser used is sufficient only to melt the powder particles. The insufficiency to penetrate results in joining the molten particles with an underlying substrate. Besides, the ball formation on the surface may also be affected by the scan speed, as reported by Aboulkhair et al. [6]. The $S_{\mathrm{PV}}$ and $S_{\mathrm{PR}}$ samples displayed similar corrosion behaviour. The surfaces of the samples subjected to salt spray tests were characterised by local corrosion: usually manifested by random formation of pits. From the high-resolution images in Fig. $5 \mathrm{c}$ and $\mathrm{n}$, pitting formation on the surface is clearly observed in the first $48 \mathrm{~h}$ exposure. The corrosion progressed along with exposure time. At the same time, simultaneous localised pit formation on the surface of the samples and refilling of the same by corrosion products occurred. Particularly, it was observed that, following the $48 \mathrm{~h}$ of exposure time, the sample surfaces were mainly characterised by corrosion products with different sizes and morphology. At the end of tests $(1000 \mathrm{~h})$, high-magnification analysis indicated that the corrosion pits became slightly more marked inside where it places the corrosion products (Fig. 5d).

For a comprehensive understanding of the corrosion behaviour of the AlSi10Mg samples subjected to the accelerated corrosion environment, both mass loss results and surface roughness analyses were performed.

Figure $6 \mathrm{a}$ and $\mathrm{b}$ is provided to show the mass loss and density values of $S_{\mathrm{PV}}$ and $S_{\mathrm{PR}}$ specimens during salt spray tests, respectively. In addition to that, the $R a$ and $R t$ surface roughness of both samples is shown in Fig. 7 .

The results of mass loss (Fig. 6a) showed that two samples follow a similar trend. As can be seen from Fig. 6a, the mass loss of the two samples were low and almost constant up to $24 \mathrm{~h}$, following this exposure time, the samples displayed mass gains with increasing exposure time. In particular, it was observed that the sign inversion, from loss to mass gain, occurs at $48 \mathrm{~h}$ of exposure time, indicating an important progressive formation of corrosion products from this time on. In addition, it was observed that following $240 \mathrm{~h}$, the mass gain amount of the $S_{\mathrm{PV}}$ sample was about $12.5 \%$ higher than the $S_{\mathrm{PR}}$ sample, reaching to $27 \%$ at the end of the maximum exposure time of the present study. In other words, both samples are characterised by the low surface defectiveness during the first $24 \mathrm{~h}$, exhibiting a corrosion rate almost constant; however, following this exposure time the samples displayed a decrease in corrosion rate as exposure time increased. Regarding the $S_{\mathrm{PR}}$ sample, a highest surface defectiveness was accounted after the first $24 \mathrm{~h}$ in the test chamber, thus exhibiting a slightly corrosion rate higher than $S_{\mathrm{PV}}$ ones.

Besides, it is worthwhile to note that density values of the samples remained constant with increasing exposure time in NSS chamber (Fig. 6b), indicating that no occurrences significantly interconnected to the formations and/or changes of open and closed porosity, which could lead to a reduction in physical properties. Moreover, the density values of samples fabricated using recycled powder $S_{\mathrm{PR}}$ is comparable to the using the virgin powder for each exposure to NSS chamber. 


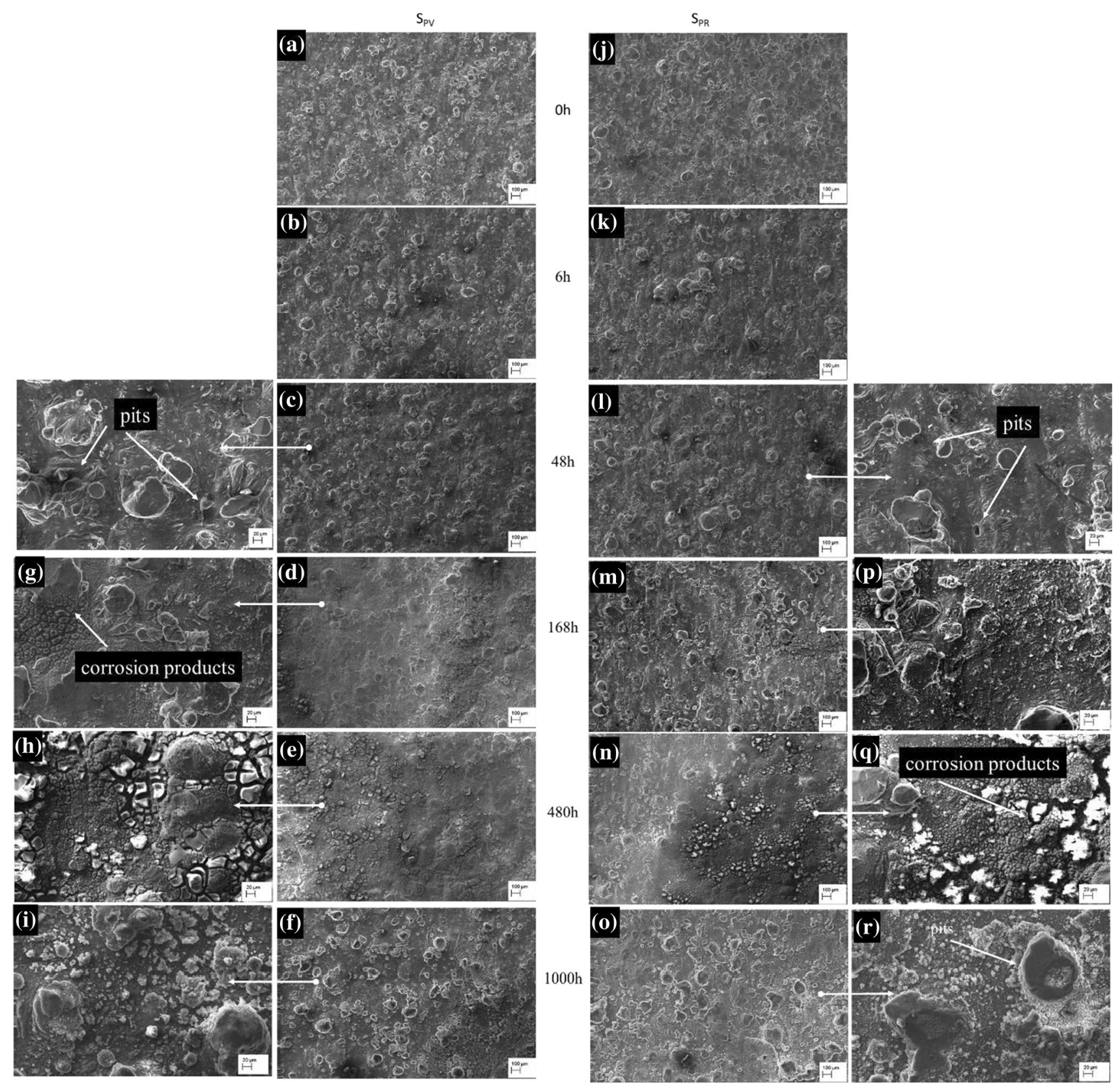

Fig. 5 Secondary SEM micrographs of SLM specimen surfaces following 6, 48, 168, 480 and $1000 \mathrm{~h}$ of salt spray tests

The graphs in Fig. 7a and b revealed that the $R a$ and $R t$ surface roughness values of $S_{\mathrm{PR}}$ is slightly higher than $S_{\mathrm{PV}}$ samples at all exposure times. The morphology of the AlSi10Mg powder, such as satellite formation and particle elongation, occur while reusing. As explained in Sect. 3.1.1., this may not affect the porosity of the material but can affect the surface roughness. Some slight fluctuations were also observed with the increasing exposure time. This behaviour is likely due to some simple considerations related to the corrosion phenomenon. During the accelerated ageing treatment, there is a concomitance of two mechanisms. One, there may be the formation of new micro-porosities (pitting) emerging on the surface as well as an increase in existing ones; on the other hand, the formation of corrosion products. In agreement with literature and SEM observation, the pits on the surface, for the longer exposure times, may also be partially filling by means of material products, whose morphological characteristics depend largely on the corrosive atmosphere that generated them, leading to a slight decrease in the roughness. This remark is also supported by SEM analyses (Fig. 5). 
(a)

Exposure time $[\mathrm{h}]$

(b)
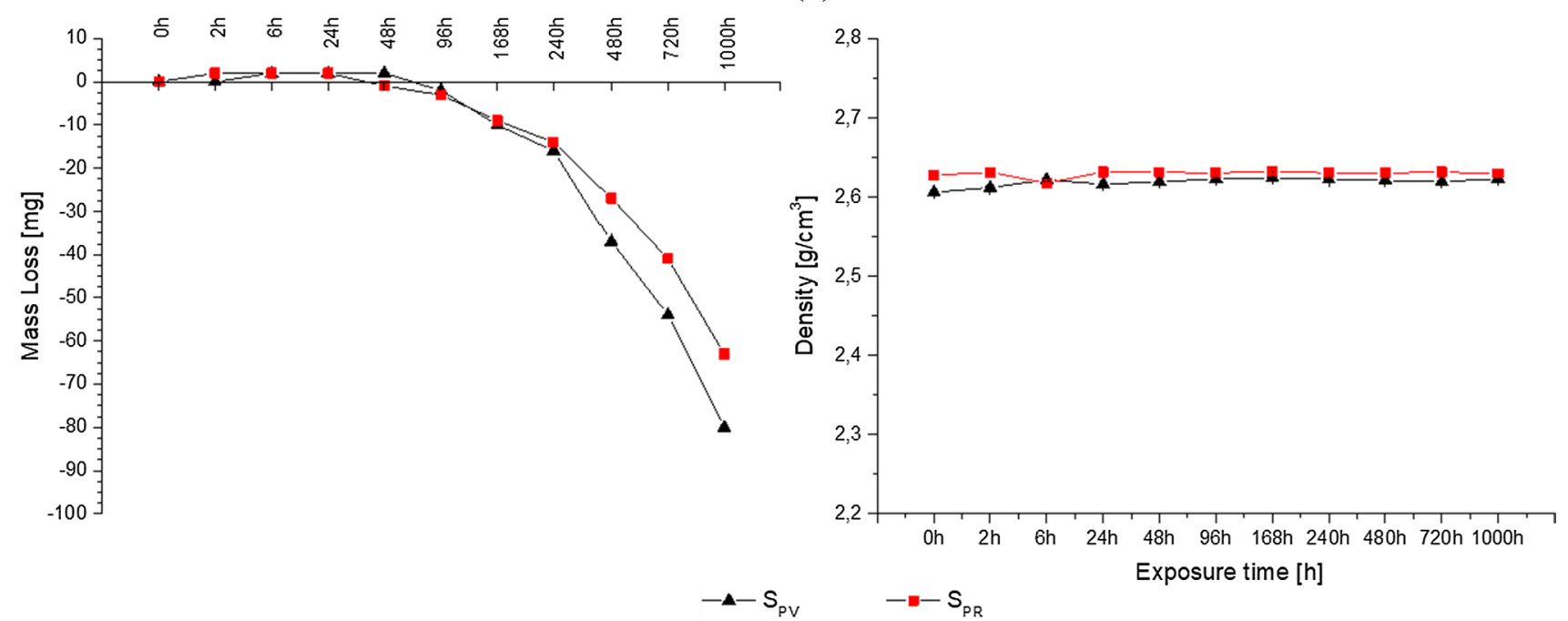

Fig. 6 Analysis of the effect of exposure to a controlled corrosive environment of the two SLM specimens: $\mathbf{a}$ mass loss and $\mathbf{b}$ density value as a function of exposure time in NSS chamber
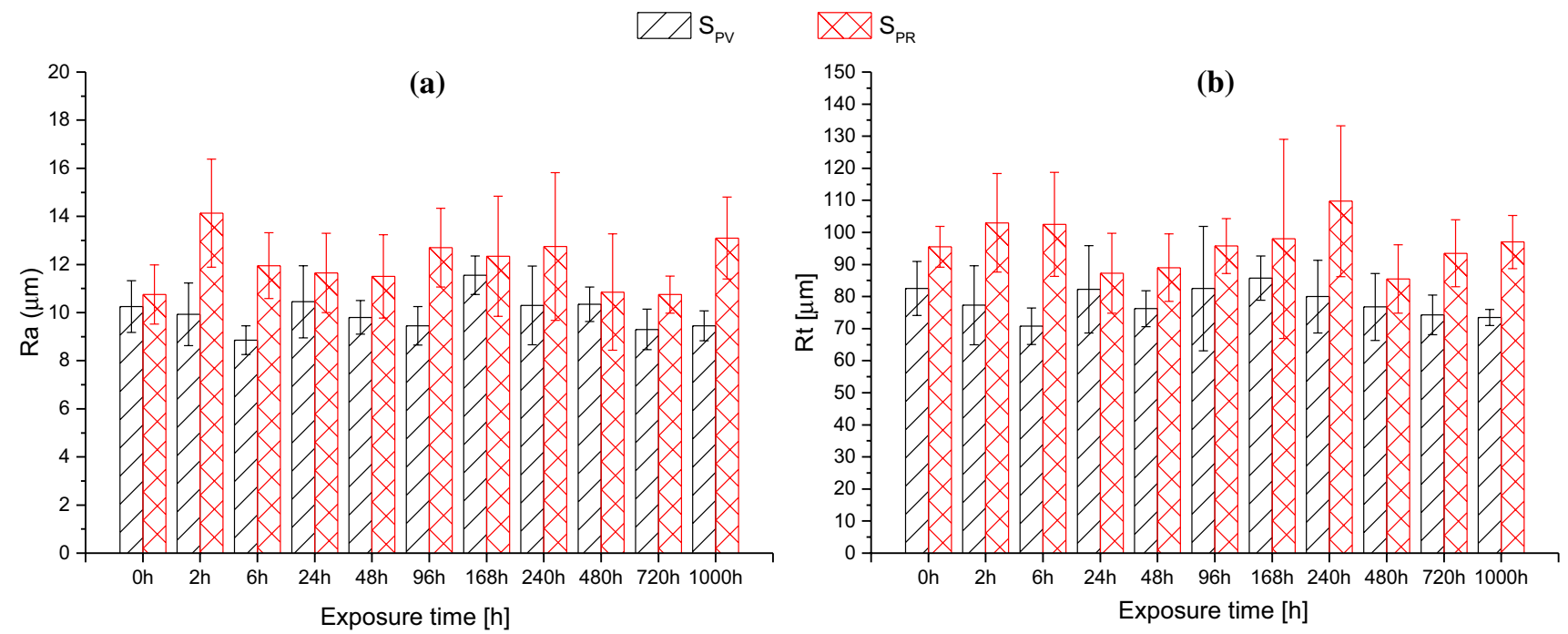

Fig. 7 Analysis of the surface roughness of $S_{\mathrm{PV}}$ and $S_{\mathrm{PR}}$ samples with respect to exposure time interval to salt spray test: a $R a$ (roughness average value) and $\mathbf{b} R t$ (roughness total height value)

Therefore, with reference to the results presented through Figs. 5, 6 and 7, it appears that the corrosion behaviour was observed to be the same for both the $S_{\mathrm{PV}}$ and $S_{\mathrm{PR}}$ samples.

\subsubsection{AE characteristics}

The acoustic signals generated in $S_{\mathrm{PR}}$ specimens exposed to the corrosion environment are recorded for its exposure time. Typically, acoustic signals are generated as a result of microcrack formation, sliding of microparticles under loading and other similar phenomena. In the case of corrosion, the formation of pits, formation of corrosion products, particularly, the spallation of corrosion products contributes to the acoustic emission. The formation of pits in the specimens exposed to the corrosion environment for more than $48 \mathrm{~h}$ is evident from Fig. 5. Similarly, the mass gain as a function of exposure time presented in Fig. 6a and the SEM micrographs in Fig. 5 explains the formation of the corrosion products. These are general contributors to the AE signals, as explained. The AE signals are characterised in terms of peak amplitude distribution, frequency centroid distribution and cumulative counts. The definitions of these parameters 
Fig. 8 Distribution of peak amplitude of the AE signals recorded from $S_{\mathrm{PR}}$ sample as a function of exposure time in the NSS chamber

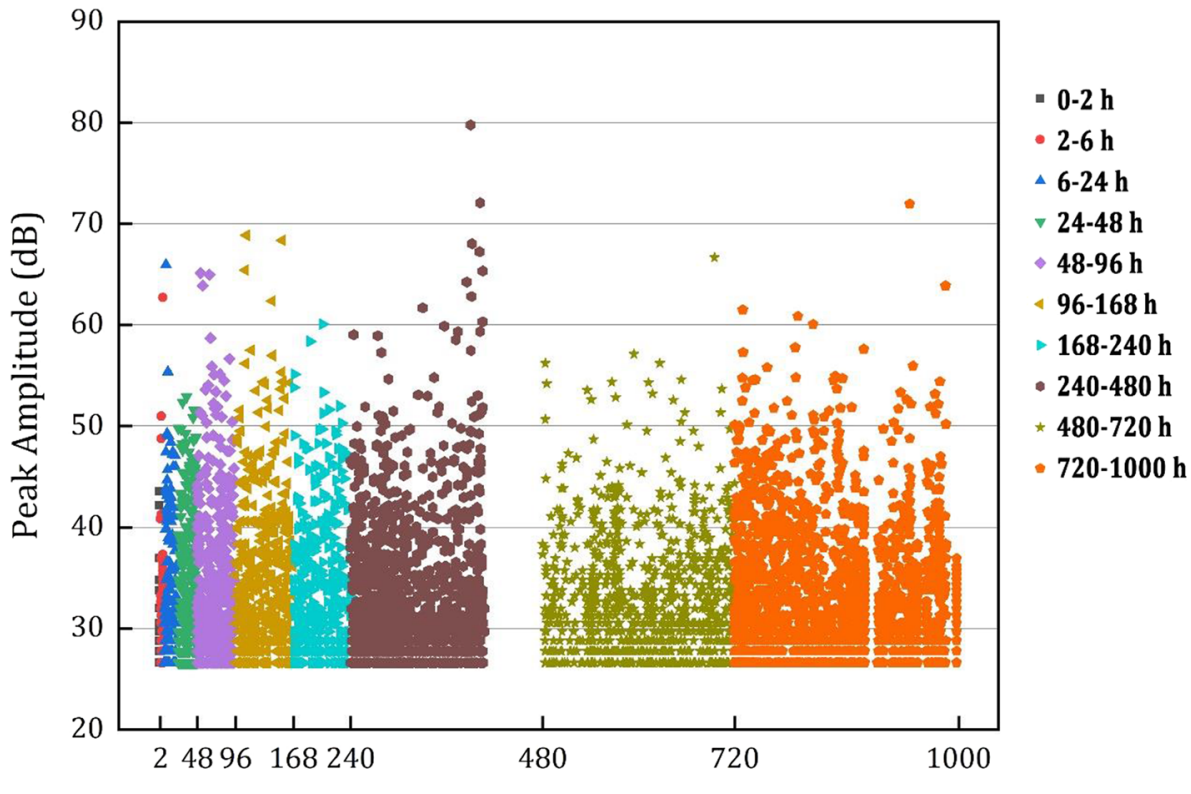

Exposure time (h) are discussed extensively in the review work by Barile et al. [32]. The peak amplitude distribution as a function of exposure time is presented in Fig. 8.

The key observations from the amplitude distribution are presented here. First, in Fig. 8, during the initial exposure time, there are very few AE signals recorded above $50 \mathrm{~dB}$. In fact, there are no AE signals recorded above $45 \mathrm{~dB}$ until $2 \mathrm{~h}$ exposure. Second, there seems to be no AE signals recorded above $25 \mathrm{~dB}$ threshold between 407 and $480 \mathrm{~h}$. This is more interesting when compared to the next stage, where there are very few AE signals recorded above $45 \mathrm{~dB}$. This seems rather interesting because during this exposure to the corrosion environment for $240 \mathrm{~h}$ (from 480 to $720 \mathrm{~h}$ ), there are very few high amplitude AE signals being recorded. The distribution of peak amplitude could not conclude the results, and thus it is compared with the distribution of frequency centroid and the cumulative counts recorded. The distribution of frequency centroid recorded from the tested specimen is presented in Fig. 9.

One of the key indications that can be observed from Fig. 9 is the abrupt change in the frequency centroid during the exposure time 48-96 h. The frequency centroid of
Fig. 9 Distribution of frequency centroid of the AE signals recorded from $S_{\mathrm{PR}}$ sample as a function of exposure time in the NSS chamber

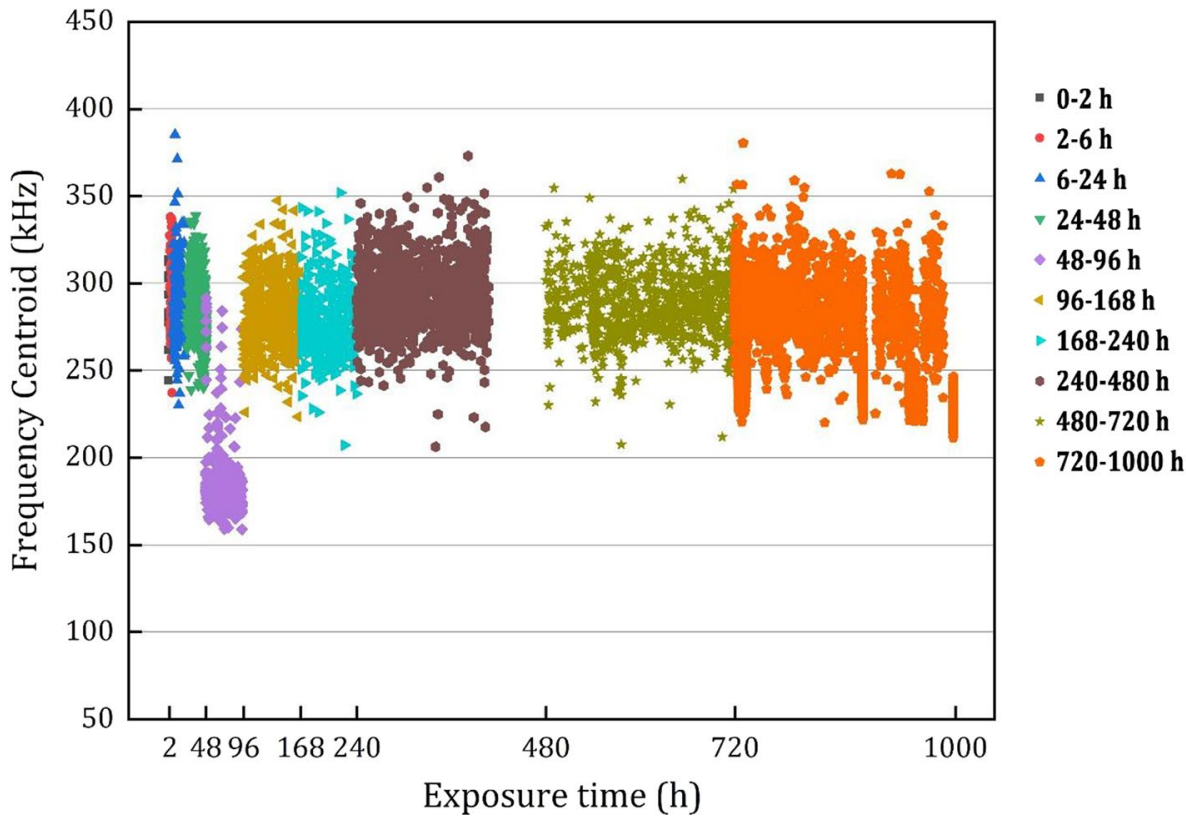


all exposure time, except for $48-96 \mathrm{~h}$ and $720-1000 \mathrm{~h}$ are centred between 250 and $350 \mathrm{kHz}$. There are quite a few $\mathrm{AE}$ signals recorded below $250 \mathrm{kHz}$ between 720 and $1000 \mathrm{~h}$. However, significantly greater percentage of AE signals recorded during 48-96 h exposure time lies between 175 and $250 \mathrm{kHz}$. First, this can be compared with the amplitude distribution in Fig. 8. Up until $48 \mathrm{~h}$ exposure time, there are very few $\mathrm{AE}$ signals recorded above $45 \mathrm{~dB}$ but it increases rapidly during the exposure time of $48-96 \mathrm{~h}$. In other words, the density of the peak amplitude distribution above $45 \mathrm{~dB}$ is large only during this particular duration (48-96 h). There also is a large anomaly in the frequency centroid during that exposure time. Now comparing these results with the SEM micrographs in Fig. 5, there clearly are the formation of pits in the samples exposed up to $96 \mathrm{~h}$. The pits started forming in the samples only after the exposure in the corrosion environment after $48 \mathrm{~h}$. Comparing the results from Figs. 5, 8 and 9 , it can be said that the formation of pits resulted in the increase in $\mathrm{AE}$ activity above $45 \mathrm{~dB}$, which has its frequency centroid centred around $175 \mathrm{kHz}$ and $250 \mathrm{kHz}$. Although there are AE signals above $45 \mathrm{~dB}$, their frequency centroid is different from the region of 48-96 h, it can possibly due to different corrosion mechanisms. Nonetheless, there exists a consensus that different damage mechanisms in different material can release AE signals with different frequency domain. This has been explained by Barile et al. [33] who tested the frequency characteristics of AE signals generated from different damage modes in AlSi10Mg specimens. Extending that consensus to the current problem, and comparing the results with SEM micrographs, it can be evidently said that the formation of pits during the exposure time of $48 \mathrm{~h}$ and $96 \mathrm{~h}$ releases AE signals with the frequency centroid around $175 \mathrm{kHz}$ and $250 \mathrm{kHz}$.

This does not necessarily mean that the formation of pits has stopped after $96 \mathrm{~h}$ duration, but rather formation of corrosion products is more significant after the duration of $96 \mathrm{~h}$. This can also be seen in SEM micrographs in Fig. 5o-q and the mass gain in Fig. 6a. The significant gain in the mass of $S_{\text {PR }}$ specimen exposed to the corrosion environment shows this evidently. In fact, large pits are observed when the samples are exposed to the corrosion environment for more than $720 \mathrm{~h}$ in Fig. 5. Similarly, a significant number of AE signals with frequency centroid below $250 \mathrm{kHz}$ is recorded during this stage, which possibly could be due to the formation of pits.

It is quite difficult to analyse all the AE signals in their frequency domain to explain this more elaborately. This is due to the large storage space and data processing time required. Therefore, the differences in the corrosion mechanisms as a function of exposure time in the NSS chamber are explained through cumulative counts. The cumulative counts of the recorded AE signals are presented in Fig. 10.

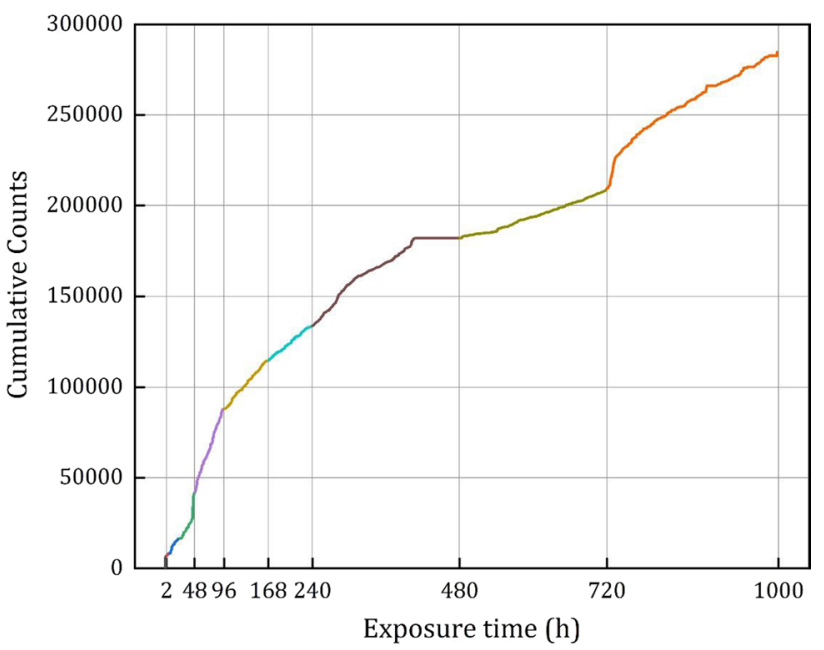

Fig. 10 Cumulative counts of the AE signals recorded from $S_{\mathrm{PR}}$ samples exposed in the NSS chamber

The different stages of corrosion in the sample exposed to the corrosion environment can be explained from Fig. 10 . Corroborating with the results from Figs. 8 and 9, there is a sudden increase in the cumulative counts near the end of $48 \mathrm{~h}$ exposure time and it increases with a larger slope until $96 \mathrm{~h}$. As explained in this section earlier, the formation of pits could be responsible for this. Similar reports by Darowicki et al. [34] suggesting that the formation of pits (in potentiodynamic corrosion) leads to the rapid increase in cumulative counts. From 96 h exposure time to 407 h, the cumulative counts seem to increase gradually with the same slope value. This is an indication of a similar corrosion mechanism progressing gradually during this stage in the specimen. The lack of acoustic activity between 407 and $480 \mathrm{~h}$ is the reason for the flatline in the cumulative counts. The interesting observation is that after $480 \mathrm{~h}$ and until $536 \mathrm{~h}$, the cumulative counts remain almost similar to a flatline explaining the lack of major acoustic activity. This coincides with the amplitude distribution in Fig. 8 where the large amplitude signal is scarce during this same period. This possibly can suggest that the corrosion mechanism starts to vary from this region. This is followed by a gradual increase in cumulative counts until $720 \mathrm{~h}$ but after that it increases sharply indicating an unstable increase in the corrosion mechanism after this exposure time. There could be some possible reasons: formation of larger pits, which are observed in Fig. 5 SEM micrographs and corroborated by the frequency centroid in Fig. 9. The probable reason for this unstable increase in cumulative counts could be correlated to the formation of pits and the corrosion products at the final exposure stage.

The different damage mechanisms and the stages of corrosion due to the exposure of the specimen have been 
explained through three different AE descriptors. The results are supported with the SEM micrographs and mass gains.

\subsubsection{Tensile properties and fracture morphology}

The effects of the exposure to the controlled corrosive environment on the mechanical behaviour of the $S_{\mathrm{PV}}$ and $S_{\mathrm{PR}}$ samples were investigated by means of tensile tests. The values of the yield stress (YS), ultimate tensile strength (UTS), Young's modulus (EI) and strain at fracture (elongation $\varepsilon \%$ ) as a function of exposure time to the NSS are presented in Fig. 11. It is known that generally, the mechanical properties of the samples are affected by several factor, such as on the densification mechanism of fabricated parts, porosity level and their microstructure resulting by SLM processing.

According to the results obtained from the hardness measurements and microstructural analysis, the tensile test results shown that the UTS, YS and EI (see Fig. 11a, b and c) of the $S_{\mathrm{PV}}$ sample were about $7 \%$ greater than the $S_{\mathrm{PR}}$ sample, as the result of the finer slight microstructure achieved in $S_{\mathrm{PV}}$ ones. Therefore, it worth to note that the slight microstructural variations occurred in the recycled samples did not play a significant role in affecting the mechanical properties of the SLM samples. Consequently, the mechanical behaviour of the as-built AlSi10Mg samples manufactured by recycled powder $S_{\mathrm{PR}}$ are comparable to the sample fabricated by virgin powder $S_{\mathrm{PV}}$. Furthermore, a closer look at the graph in Fig. 11d reveals that $S_{\mathrm{PV}}$ sample differed from one another mainly in the strain at fracture $(\varepsilon \%)$ values. Particularly, it was observed that the $S_{\mathrm{PV}}$ samples exhibited a loss of ductility respect to the $S_{\mathrm{PR}}$ (Fig. 11d). The loss of ductility with respect to $S_{\mathrm{PR}}$ was due to slightly greater porosity percent within the sample (see Table 2). Porosity within the sample led to stress concentration, so the crack could possibly be initiated from the pores and propagated throughout the thickness of the sample.

Regarding the corrosion behaviour of the samples, the $S_{\mathrm{PV}}$ sample always displayed slightly superior YS, UTS and EI
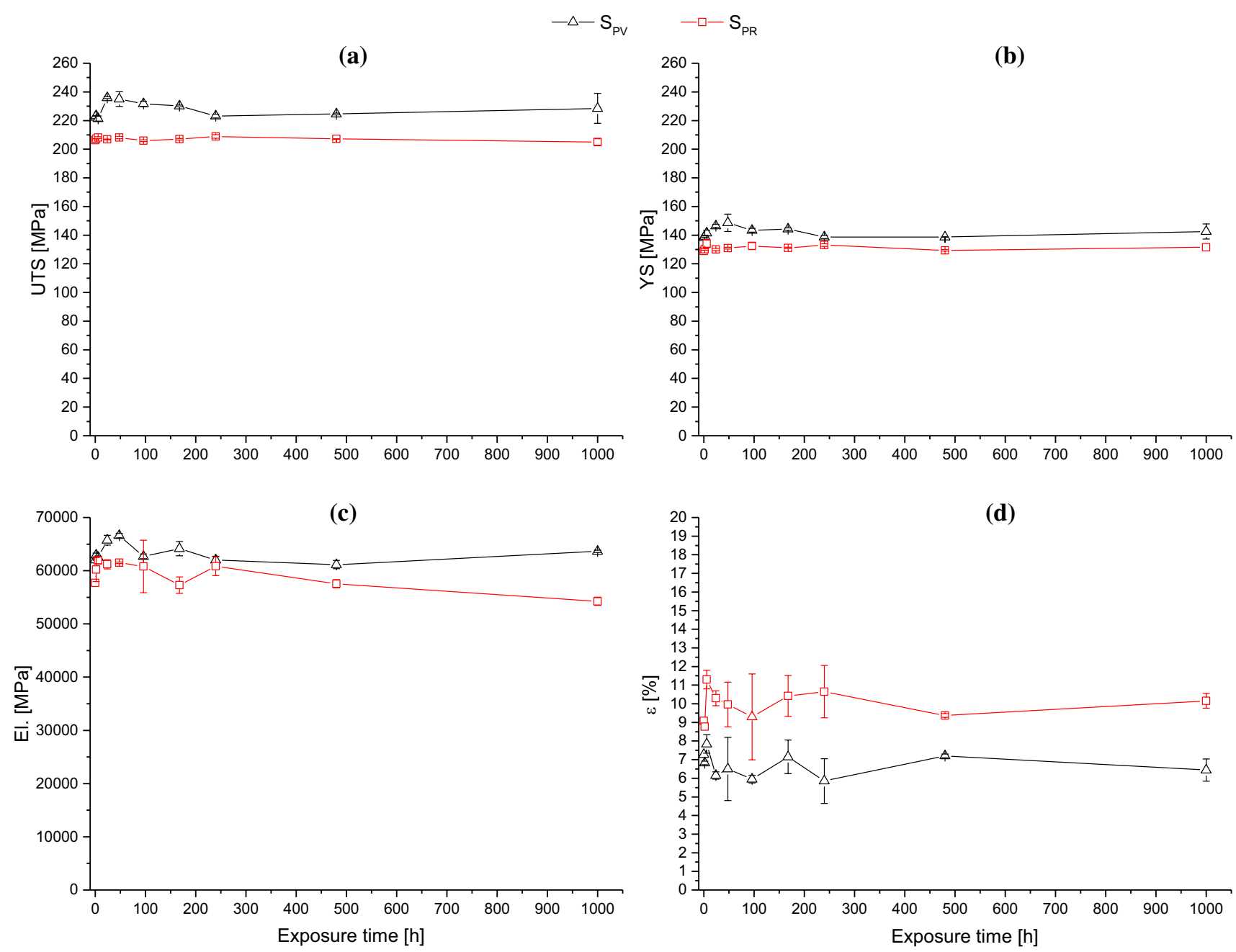

Fig. 11 Mechanical properties of two specimens as a function of exposure time in salt spray testing: a ultimate tensile strength (UTS), b yield stress (YS); c Young's modulus (El.); d strain at fracture ( $\varepsilon \%)$ 
values following each exposure time in the corrosion process, while $S_{\mathrm{PR}}$ samples always exhibited greatest $\varepsilon \%$ values. Moreover, the results indicate that the UTS and YS did not change with the exposure time to the accelerated corrosion treatment, and this was observed for $S_{\mathrm{PR}}$ samples. On the other hand, a fluctuation of the UTS, YS and EI values at the exposure intervals of 24 and $48 \mathrm{~h}$ in the corrosion chamber for $S_{\mathrm{PV}}$ samples was observed. Furthermore, it can be observed that also the EI value fluctuates slightly following each exposure time in the corrosion process. In particular, the variation was greatly observed during the first corrosion steps (24-96 h). This behaviour could probably be a result of the corrosion products formation which completely close the microporosity on the sample surface during the very first steps, promoting the slight increase in EI. Since ductility is connected to roughness and porosity, the $\varepsilon \%$ shows the same fluctuation observed for the roughness of samples exposed to corrosion. In other word the fluctuation of the $\varepsilon \%$ values have been ascribed to simultaneous localised pits formation on the surface of the samples and refilling of the same by corrosion products.

Nevertheless, the observed variation at the exposure intervals of 24 and $48 \mathrm{~h}$ in the corrosion chamber was less than $8 \%$, which is not a significant reduction. Therefore, results presented here confirmed that the exposure to a corrosive environment of dense saltwater fog did not deteriorate the mechanical performance of $S_{\mathrm{PV}}$ and $S_{\mathrm{PR}}$ samples. In addition, as briefed in the earlier sections, the corrosion behaviour for samples $S_{\mathrm{PV}}$ and $S_{\mathrm{PR}}$ also are very similar, implying that there is no dependence on the origin of the powder used.

In Fig. 12, the SEM images of fracture surfaces of both $S_{\mathrm{PV}}$ and $S_{\mathrm{PR}}$ as-built samples are presented. It can be observed that the samples exhibit a very similar fracture. The fractographic analysis of the specimens revealed that the failure always occurred in the gauge length. Moreover, Fig. 12a and $b$ displays that the fracture edges were transversal to the
Fig. 12 SEM images of fracture heads of SLM AlSi10Mg specimens after $1000 \mathrm{~h}$ of salt spray tests. SEM macrograph of fracture head in longitudinal section (LT-L plane): a $S_{\mathrm{PV}}$ sample and $\mathbf{b} S_{\mathrm{PR}}$ sample. SEM micrographs of fracture heads in cross-section (ST-LT plane): c $S_{\mathrm{PV}}$ sample and $\mathbf{d} S_{\mathrm{PR}}$ sample. e, $\mathbf{f}, \mathbf{g}$ and $\mathbf{h}$ High magnifications of the spot fringe of fracture head of samples
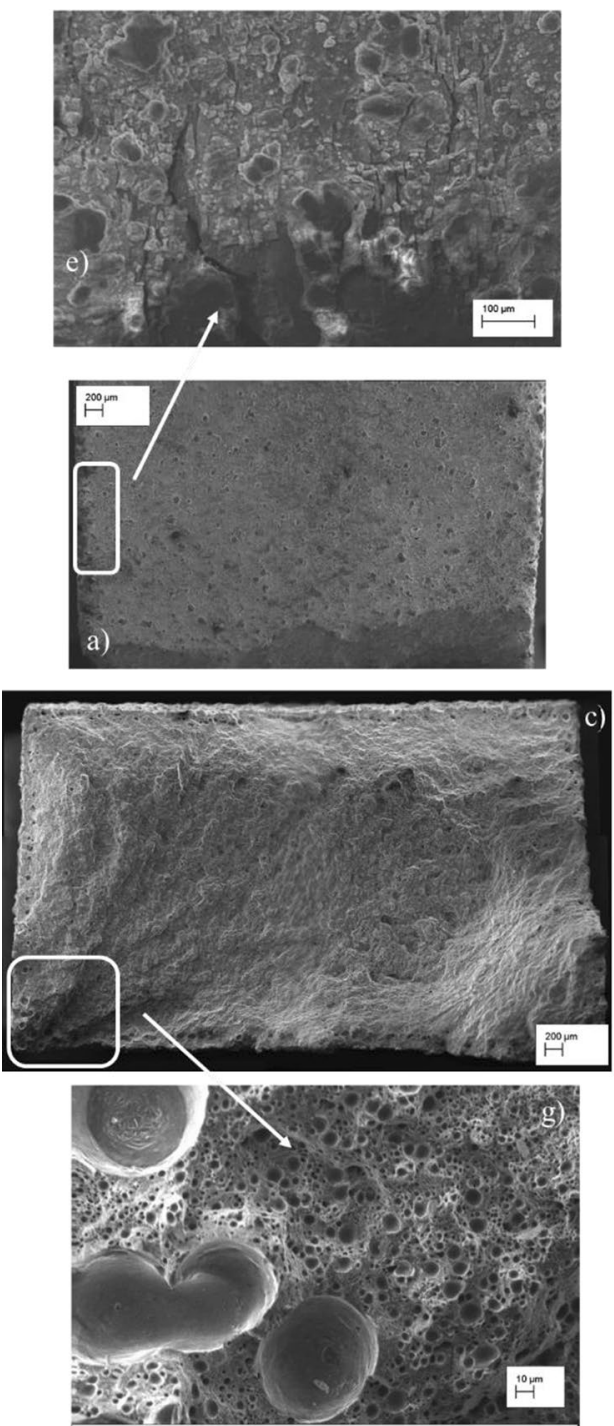
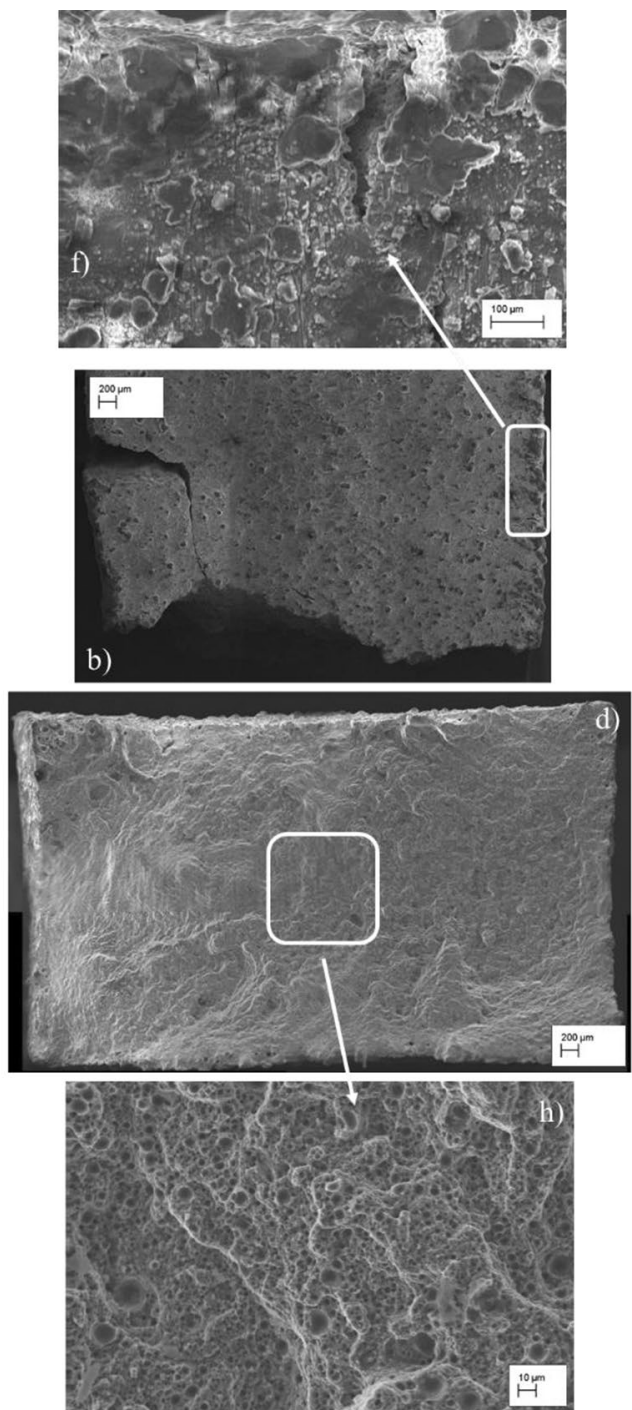
tensile axis without necking evidence. The fracture surfaces analyses of $S_{\mathrm{PV}}$ and $S_{\mathrm{PR}}$ samples show features of ductile fracture with many small and shallow dimples, uniformly distributed over the entire fracture surface (Fig. 12g and h). In samples' longitudinal section, it seems that the failure initiated at samples edges and then propagated perpendicular to the applied tensile load. This is related to the presence of pores mainly distributed along samples edges. In fact, samples' cross-section shows numerous circular pores, also found during metallographic analysis.

Therefore, the rupture was mainly due to stress concentration around these defects.

\section{Conclusions}

This paper is devoted to study the microstructural evolution and corrosion-resistance behaviour of the SLM manufactured AlSi10Mg aluminium alloy using virgin and recycled powders. Based on the analysis of results, the following conclusions can be drawn:

1. Regardless of the virgin or recycled AlSi10Mg aluminium alloy powders used, the microstructures of the fabricated SLM samples are extremely fine due to the rapid solidification. Furthermore, microstructural analysis results show that using the recycled powder in the fabrication of the alloy leads to slight coarsening of the interdendritic Si-network in the structure, mostly along the melt pool boundaries.

2. The tensile test results show that the use of recycled powder does not significantly affect the mechanical properties of the test samples.

3. No considerable influences of the powders used on the corrosion behaviour of the specimens are detected. Regardless of the origin of the powders, the SLM samples exposed to the corrosive environment of dense saltwater fog up to $1000 \mathrm{~h}$ does not undergo any substantial changes in mechanical properties confirming a good stability of structural behaviour.

4. The acoustic emission results show the different corrosion progression in the AlSi10Mg sample over the exposure to the saltwater fog. The SEM micrographs and the mass gain of the sample exposed to the corrosion environment show a strong correlation with the acoustic emission results.

Therefore, this study promotes the feasibility of using recycled powder in SLM process without any detrimental effect on the quality of the final product.
Data availability The raw/processed data required to reproduce these findings cannot be shared at this time as the data also form part of an ongoing study.

\section{Declarations}

Conflict of interest The authors and the co-authors declare no conflict of interest.

Open Access This article is licensed under a Creative Commons Attribution 4.0 International License, which permits use, sharing, adaptation, distribution and reproduction in any medium or format, as long as you give appropriate credit to the original author(s) and the source, provide a link to the Creative Commons licence, and indicate if changes were made. The images or other third party material in this article are included in the article's Creative Commons licence, unless indicated otherwise in a credit line to the material. If material is not included in the article's Creative Commons licence and your intended use is not permitted by statutory regulation or exceeds the permitted use, you will need to obtain permission directly from the copyright holder. To view a copy of this licence, visit http://creativecommons.org/licenses/by/4.0/.

\section{References}

1. Yusuf SM, Hoegden M, Gao N. Effect of sample orientation on the microstructure and microhardness of additively manufactured AlSi10Mg processed by high-pressure torsion. Int J Adv Manuf Technol. 2020;106(9):4321-37.

2. Ardila LC, Garciandia F, González-Díaz JB, Álvarez P, Echeverria A, Petite MM, et al. Effect of IN718 recycled powder reuse on properties of parts manufactured by means of selective laser melting. Phys Procedia. 2014;56:99-107.

3. Tang HP, Qian M, Liu N, Zhang XZ, Yang GY, Wang J. Effect of powder reuse times on additive manufacturing of Ti-6Al-4V by selective electron beam melting. JOM. 2015;67(3):555-63.

4. Rafieazad M, Chatterjee A, Nasiri AM. Effects of recycled powder on solidification defects, microstructure, and corrosion properties of DMLS fabricated AlSi10Mg. JOM. 2019;71(9):3241-52.

5. Asgari H, Baxter C, Hosseinkhani K, Mohammadi M. On microstructure and mechanical properties of additively manufactured AlSi10Mg_200C using recycled powder. Mater Sci Eng A. 2017;707:148-58.

6. Aboulkhair NT, Maskery I, Tuck C, Ashcroft I, Everitt NM. On the formation of AlSi10Mg single tracks and layers in selective laser melting: microstructure and nano-mechanical properties. J Mater Process Technol. 2016;230:88-98.

7. Olakanmi EO. Selective laser sintering/melting (SLS/SLM) of pure Al, Al-Mg, and Al-Si powders: effect of processing conditions and powder properties. J Mater Process Technol. 2013;213(8):1387-405.

8. Barile C, Casavola C, Campanelli SL, Renna G. Analysis of corrosion on sintered stainless steel: mechanical and physical aspects. Eng Fail Anal. 2019;95:273-82.

9. Tan Q, Liu Y, Fan Z, Zhang J, Yin Y, Zhang M-X. Effect of processing parameters on the densification of an additively manufactured 2024 Al alloy. J Mater Sci Technol. 2020;58:34-45.

10. Campbell FC Jr. Manufacturing technology for aerospace structural materials. Amsterdam: Elsevier; 2011.

11. Renna G, Leo P, Casavola C. Effect of ElectroSpark process parameters on the WE43 magnesium alloy deposition quality. Appl Sci. 2019;9(20):4383. 
12. Revilla RI, Liang J, Godet S, de Graeve I. Local corrosion behavior of additive manufactured AlSiMg alloy assessed by SEM and SKPFM. J Electrochem Soc. 2016;164(2):C27.

13. Porter DA, Easterling KE. Phase transformations in metals and alloys (revised reprint). Boca Raton: CRC Press; 2009.

14. Dong S, Zhang X, Ma F, Jiang J, Yang W, Lin Z. Research on metallurgical bonding of selective laser melted AlSi10Mg alloy. Mater Res Express. 2020;7(2):025801.

15. Maamoun AH, Elbestawi M, Dosbaeva GK, Veldhuis SC. Thermal post-processing of $\mathrm{AlSi} 10 \mathrm{Mg}$ parts produced by Selective Laser Melting using recycled powder. Addit Manuf. 2018;21:234-47.

16. Kempen K, Thijs L, van Humbeeck J, Kruth J-P. Mechanical properties of AlSi10Mg produced by selective laser melting. Phys Procedia. 2012;39:439-46.

17. Louvis E, Fox P, Sutcliffe CJ. Selective laser melting of aluminium components. J Mater Process Technol. 2011;211(2):275-84.

18. Trevisan F, Calignano F, Lorusso M, Pakkanen J, Aversa A, Ambrosio EP, et al. On the selective laser melting (SLM) of the AlSi10Mg alloy: process, microstructure, and mechanical properties. Materials. 2017;10(1):76.

19. Weingarten C, Buchbinder D, Pirch N, Meiners W, Wissenbach K, Poprawe R. Formation and reduction of hydrogen porosity during selective laser melting of AlSi10Mg. J Mater Process Technol. 2015;221:112-20.

20. Rosenthal I, Stern A, Frage N. Strain rate sensitivity and fracture mechanism of AlSi10Mg parts produced by selective laser melting. Mater Sci Eng A. 2017;682:509-17.

21. Zhao X, Song B, Fan W, Zhang Y, Shi Y. Selective laser melting of carbon/A1Si10Mg composites: Microstructure, mechanical and electronical properties. J Alloy Compd. 2016;665:271-81.

22. Barile C, Casavola C, Moramarco V, Vimalathithan PK. A comprehensive study of mechanical and acoustic properties of selective laser melting material. Arch Civil Mech Eng. 2020;20(1):1-11.

23. ASTM B. Standard practice for operating salt spray (fog) apparatus. ASTM International (1997 Edition). 2011.

24. STANDARD B, ISO B. Corrosion tests in artificial atmospheresSalt spray tests. 2006.
25. Tan JH, Wong WLE, Dalgarno KW. An overview of powder granulometry on feedstock and part performance in the selective laser melting process. Addit Manuf. 2017;18:228-55.

26. Read N, Wang W, Essa K, Attallah MM. Selective laser melting of AlSi10Mg alloy: process optimisation and mechanical properties development. Mater Des (1980-2015). 2015;65:417-24.

27. Aboulkhair NT, Everitt NM, Ashcroft I, Tuck C. Reducing porosity in AlSi10Mg parts processed by selective laser melting. Addit Manuf. 2014;1:77-86.

28. Cordova L, Campos M, Tinga T. Revealing the effects of powder reuse for selective laser melting by powder characterization. JOM. 2019;71(3):1062-72.

29. Thijs L, Kempen K, Kruth J-P, van Humbeeck J. Fine-structured aluminium products with controllable texture by selective laser melting of pre-alloyed AlSi10Mg powder. Acta Mater. 2013;61(5):1809-19.

30. Revilla RI, Verkens D, Rubben T, de Graeve I. Corrosion and corrosion protection of additively manufactured aluminium alloys-a critical review. Materials. 2020;13(21):4804.

31. Tolochko NK, Mozzharov SE, Yadroitsev IA, Laoui T, Froyen L, Titov VI, et al. Balling processes during selective laser treatment of powders. Rapid Prototyp J. 2004. https://doi.org/10.1108/13552 540410526953

32. Barile C, Casavola C, Pappalettera G, Kannan VP. Application of different acoustic emission descriptors in damage assessment of fiber reinforced plastics: a comprehensive review. Eng Fract Mech. 2020;235:107083.

33. Barile C, Casavola C, Pappalettera G, Vimalathithan PK. Acoustic emission descriptors for the mechanical behavior of selective laser melted samples: an innovative approach. Mech Mater. 2020;148: 103448 .

34. Darowicki K, Mirakowski A, Krakowiak S. Investigation of pitting corrosion of stainless steel by means of acoustic emission and potentiodynamic methods. Corros Sci. 2003;45(8):1747-56.

Publisher's Note Springer Nature remains neutral with regard to jurisdictional claims in published maps and institutional affiliations. 